\title{
RETOS DE LA TRADUCCIÓN DEL IMAGINARIO CREOLE: NEGOCIAR LA DISTANCIA ENUNCIATIVA ENTRE TEXTO ORIGINAL HETEROLINGÜE Y TRADUCCIÓN
}

\author{
THE CHALLENGES OF TRANSLATING CREOLE IMAGINARY: THE \\ REGULATION OF ENUNCIATIVE DISTANCE BETWEEN THE \\ HETEROLINGUAL SOURCE TEXT AND THE TRANSLATION
}

\author{
DESAFIOS DA TRADUÇÃO DO IMAGINÁRIO CRIOULO: NEGOCIAR A \\ DISTÂNCIA ENUNCIATIVA ENTRE O TEXTO HETEROLINGUE ORIGINAL E \\ A TRADUÇÃO
}

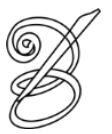 \\ María Eugenia GHIRIMOLDI ${ }^{1}$ \\ Universidad Nacional de La Plata, Argentina
}

\begin{abstract}
Resumen: Presentamos en este artículo uno de los aspectos que emergen del análisis de las traducciones de textos literarios heterolingües: la dimensión enunciativa del texto traducido ${ }^{2}$. Siguiendo a Suchet (2010), analizamos la postura del responsable del texto meta o segunda enunciación, y su relación con la instancia enunciativa primera del texto fuente. Nos ocupamos de la escritura de uno de los representantes de la literatura antillana contemporánea, Patrick Chamoiseau, en una de sus novelas galardonadas con el premio Goncourt el año de su publicación, 1992, Texaco, y su versión española de 1994, traducida por Emma Calatayud. Junto con Jean Bernabé y Raphaël Confiant, Chamoiseau es uno de los impulsores del movimiento de la Creolidad, que persigue la reivindicación de la identidad y del imaginario antillano. En este contexto, en una primera etapa, abordamos las representaciones de la escritura y del escritor en un campo literario en construcción, el valor simbólico de las lenguas de escritura, los fenómenos heterolingües del original y la gestión de la alteridad en la traducción. En una segunda etapa, analizamos la gestión de la distancia enunciativa entre ambos textos donde es posible distinguir diferentes modos de negociación. Para la confección del corpus seleccionamos algunos fragmentos representativos del imaginario creole martiniqueño como la sabiduría vegetal y las creencias mágico-religiosas. Nuestro objetivo es doble: (1) identificar el /los tipo/s de ethos que se manifiesta/n en el texto traducido y (2) poner a prueba una herramienta de análisis que parte de la práctica de la traducción y contribuye a su redefinición como espacio de transformación que se abre al Otro en múltiples direcciones.
\end{abstract}

Palabras-clave: Creolidad. Lengua creole. Ethos. Heterolingüismo. Distancia enunciativa.

Abstract:This paper presents one of the aspects arising from the analysis of the translation of heterolingual texts: the enunciative dimension of the translated text ${ }^{[3]}$. Following Suchet (2010), the analysis focuses on the position of the responsible for the target text or second enunciation, and their relation with the enunciative instance in the source text. The study explores the work of Patrick Chamoiseau, one of the representatives of contemporary Antillean literature. More specifically, attention is given to his novel Texaco, which was awarded the Prix Goncourt in 1992, the same year of its publication, and to its Spanish translation by Emma Calatayud, done in 1994. Together with Jean Bernabé and Raphaël Confiant, Chamoiseau is one of the promoters of the créolité movement, which seeks the vindication of the Antillean identity and imaginary. In this context, we firstly examine the representations of both writing and the writer in this growing literary field, the symbolic value of the languages used, heterolingual phenomena in the source text and the management of alterity in the translation. Secondly, we analyse the regulation of enunciative distance between both texts, which enables the identification of different

GHIRIMOLDI. Retos de la traducción del imaginario creole: negociar la distancia enunciativa entre texto original heterolingüe y traducción

Belas Infiéis, v. 8, n. 2, pp. 51-70, 2019. DOI: 10.26512/belasinfieis.v8.n2.2019.24378 
modes of negotiation. In building our corpus of study, we have selected some representative fragments of the Creole Martinican imaginary such as green wisdom and magic-religious beliefs. Our goal is twofold: (1) to identify the type/s of ethos materialized in the translated text; (2) to test an analytical tool which, springing from the practice of translation, contributes to the redefinition of translation as a space of transformation opening to the Other in multiple directions.

Keywords : Créolité. Creole language. Ethos. Heterolingualism. Enunciative distance.

Resumo:Apresentamos neste artigo um dos aspectos que emergem da análise das traduções de textos literários heterolingues: a dimensão enunciativa do texto traduzido ${ }^{4}$. Seguindo Suchet (2010), analisamos a posição do responsável pelo texto alvo ou segunda enunciação e sua relação com a primeira instância enunciativa do texto fonte. Focalizamos na escrita de um dos representantes da Literatura Antilhana Contemporânea, Patrick Chamoiseau, em um de seus romances, Texaco (1992), consagrado com o prêmio Goncourt no ano de sua publicação, e na sua versão em espanhol de 1994, traduzida por Emma Calatayud. Em associação com Jean Bernabé e Raphaël Confiant, Chamoiseau é um dos precursores do movimento da Crioulidade que busca a reivindicação da identidade e da imaginação antilhana. Neste contexto, em uma primeira etapa, abordamos as representações da escrita e do escritor em um campo literário em construção, o valor simbólico das línguas de escrita, os fenômenos heterolingues do texto original e o gerenciamento da alteridade na tradução. Em uma segunda etapa, analisamos o manejo da distância enunciativa entre ambos os textos, por meio do qual é possível diferenciarmos diversos modos de negociação. Para a elaboração do corpus, selecionamos alguns fragmentos representativos do imaginário crioulo-martinicano, como a sabedoria vegetal e as crenças mágico-religiosas. Nosso objetivo é duplo: (1) identificar o(s) de tipo(s) de ethos que se manifesta $(m)$ no texto traduzido e (2) pôr à prova uma ferramenta de análise que parte da prática da tradução e contribui para sua redefinição como espaço de transformação que se abre ao Outro em múltiplas direções.

Palavras-chaves: Crioulidade. Língua crioula. Ethos. Heterolinguismo. Distância enunciativa.

RECEBIDO EM: 5 de julho de 2018

ACEITO EM: 10 de outubro de 2018

PUBLICADO EM: abril 2019

GHIRIMOLDI. Retos de la traducción del imaginario creole: negociar la distancia enunciativa entre texto original heterolingüe y traducción

Belas Infiéis, v. 8, n. 2, pp. 51-70, 2019. DOI: 10.26512/belasinfieis.v8.n2.2019.24378 


\section{Introducción}

$\mathrm{P}$ resentamos uno de los aspectos que emergen del análisis de las traducciones de textos literarios heterolingües: la dimensión enunciativa del texto traducido. Nos ocupamos de la escritura de uno de los representantes de la literatura antillana contemporánea, Patrick Chamoiseau, en Texaco (premio Goncourt el año de su publicación, 1992), y su versión española de 1994, traducida por Emma Calatayud. Comenzamos con el contexto sociolingüístico de la literatura antillana y las nociones de heterolingüismo y de gestión de la distancia enunciativa en la traducción (apartados 1 y 2). Luego definiremos la metodología utilizada (apartado 3) para el siguiente análisis de la traducción del heterolingüismo del corpus elegido (apartado 4). Terminamos con la discusión del tipo de ethos diferencial que se manifiesta/n en el texto traducido (apartado 5).

\section{Contexto socio-lingüístico de la escritura antillana}

Abordar el análisis de la traducción de un texto literario antillano como el del escritor martiniqueño Patrick Chamoiseau, la novela Texaco, nos abre la puerta hacia varios puntos convergentes de reflexión: 1 . la reivindicación del ser creole ${ }^{1} ; 2$. la construcción de un campo literario; 3. la escritura híbrida en el cruce de lenguas y culturas; y 4. el texto literario heterolingüe.

\section{1 Reivindicación del ser creole.}

Junto con Jean Bernabé y Raphaël Confiant, Patrick Chamoiseau es autor del manifiesto literario Elogio de la creolidad (1989, traducción al español de 2011), cuyos principales componentes son la construcción de la identidad y la defensa de una lengua plural, un espacio donde se valoriza la mezcla, lo diverso, la Diversalité ${ }^{2}$. La novela Texaco refleja esa identidad creole múltiple a través de una escritura inestable, sinuosa, situada entre la frontera de lo escrito y lo oral. Galardonada en 1992 con el Premio Goncourt, Texaco pone en marcha las reglas de la oraliture o la literatura de la oralidad. En el ensayo que escribe junto con Confiant, Lettres créoles (1999), Chamoiseau explica que la oraliture nace con el cuentista creole, en el sistema de plantaciones, dentro de y contra la esclavitud, en una dinámica cuestionadora que acepta y rechaza. El cuentista creole, en la noche de la habitación colonial de los siglos XVII y XVIII: 
de los proverbios, de las canciones, de las rimas que eleva a la literatura, o más exactamente, a la oralitura. Receptáculo, relevo, transmisor o más exactamente propagador de una lectura colectiva del mundo, este es nuestro cuentista creole (CHAMOISEAU, 1999, p. 72-73) ${ }^{3}$.

La novela Texaco despliega diversas figuras de escritores cuya función es transmitir la palabra oral, entre los que se destacan Oiseau de Cham y Marie-Sophie Laborieux. El primero, narrador de primer grado, aparece como el Escribidor de palabras, cuya misión es "escribir la palabra oral", reflejando el mundo mágico y natural típico de la cultura creole. En efecto, se ocupa de retransmitir la palabra de Marie-Sophie, la Informadora, ícono de la oralidad martiniqueña, a quien incita a anotar sus recuerdos en cuadernos que figurarán luego citados como fuente de sus historias, siendo narradora en segundo grado. Por su parte, Esternome, el padre de la heroína, sería el tercer narrador, quien transmite sus recuerdos a la hija. Estas diferentes instancias narrativas son una muestra de la representación del autor en la novela antillana contemporánea.

Como lo caracteriza Dominique Chancé, se trata de un autor que padece ${ }^{4}$, que al no pertenecer a un campo literario canonizado, se oculta detrás de la postura del "escribidor de palabras". Un nuevo tipo de narrador es necesario para reapropiarse de una historia alienada por la crónica colonial. Pero quien lleva adelante el relato de la verdadera historia de la Martinica sufre por las contradicciones y tensiones que surgen de dar testimonio del imaginario creole oral por un lado, en la lengua del opresor, y por otro, a través del escrito.

\section{2 Construcción de un campo literario.}

Desprovista de instituciones propias, la literatura antillana es declarada por los mismos autores del Elogio como inexistente:

La literatura antillana no existe todavía. Estamos aún en un estado de preliteratura: el de una producción escrita, sin público local, que desconoce la interacción entre autores y lectores en la que se elabora cualquier literatura (BERNABÉ; CHAMOISEAU; CONFIANT, 2011, p. 11).

Esta declaración por la negativa, como afirma Mireille Rosello (1992/2017), permite sacarla de la inexistencia y abrir el debate para su defensa. Sí existe una literatura antillana a partir del siglo XVII, en francés y con una mirada occidental, lo que da lugar a los movimientos que reaccionaron ante esta situación. Una decena de jóvenes martiniqueños firmaron en 1932 su Légitime Défense, manifiesto en lucha contra la monumental alienación cultural y la 
francisación. Le sigue el de la Negritud, liderado por Aimé Césaire que entre su mirada idealizada de África y las imágenes de la miseria de su isla natal, percibirá el grito de los olvidados de los barcos negreros que plasmará en su Cahier d'un retour au pays natal publicado en 1939. Superando la mirada hacia Europa y luego hacia África, emerge la Antillanidad de Édouard Glissant que promueve una escritura nutrida de lo real antillano y que reacciona, como lo explica en su Poética de lo Diverso, contra la imposición de la lengua del colonizador (GLISSANT, 1996, p. 120).

\section{3 Escritura híbrida}

En este camino de revalorización cultural, la originalidad del autor consiste en la introducción de la lengua creole en la lengua francesa, un proceso presente a lo largo de toda la novela donde, retomando la expresión de Bernabé, el francés es fecundado por el creole (BERNABÉ, 1992, p. 35). Como señala Noemí Auzás (2017) en su artículo sobre la evolución en la inserción del creole que hace Chamoiseau en sus obras, esta fusión o mezcla de creole y francés le permite al lector de Texaco escuchar la música tan particular del creole, una lengua que se vuelve visible y audible en la voz de sus personajes. El texto está pincelado por palabras en creole que permiten ilustrar las costumbres, las emociones y todo aquello que no tiene equivalente en francés. Además del ámbito de la flora, la fauna y la alimentación, el de las tradiciones populares constituye un lugar de privilegio donde reluce la lengua creole. Estos diversos campos semánticos diseñan una imagen de la Martinica en la mente del lector, dejando la impresión de una cultura irreductible y difícil de expresar en otra lengua (AUZÁS, 2017, p. 110-111).

Esta lengua mestiza que construye Chamoiseau en la novela, o híbrida, como prefiere llamarla Lewis (2003, p. 93), se caracteriza no sólo por la inserción de palabras o fragmentos en creole sino por diferentes fenómenos lingüísticos que involucran varios componentes de la gramática: sintaxis, semántica, léxico, morfología, fonología y pragmática. Lo más destacable es el empleo del francés que lleva la marca del creole, como por ejemplo con la introducción de la partícula negativa "hak" (Ninon n'entendait hak, Ninon no hacía ni caso), diversos mecanismos para formar palabras típicos del creole utilizados en francés como la aglutinación (la crête douloudouce des plaisirs, la cresta dolodulce de los placeres), la composición de palabras (vieux-corps, ancianos), las series verbales calcadas del creole (ça tournait-virait, daban vueltas y cambiaban de rumbo), arcaísmos franceses en uso en creole (crier, en creole 
kriyé, llamar/llamarse), onomatopeyas del creole (kussu kussu, susurrar), etc. (Estos fenómenos han sido estudiados por varios autores: DESMET ARGAIN, 2015; N'ZENGOU-TAYOU, 1996).

\section{4 Texto literario heterolingüe}

Esta presencia de fenómenos lingüísticos provenientes de otra lengua en el texto escrito encuentra su definición en la noción de heterolingüismo desarrollada en 1997 por Rainier Grutman, una estrategia textual de hibridación lingüística que surge como reacción a la imposición de una lengua dominante y típica de la escritura post-colonial. Como sostiene Suchet (2010), el texto heterolingüe ofrece la base para repensar nuevos modelos para la teoría y la práctica de la traducción, desde el momento mismo en que invalida la distinción entre texto fuente y meta dado que estos textos presentan un continuo de variación entre las lenguas. Debido a este tipo de escritura es posible considerar a Chamoiseau como un traductor que produce una transferencia intertextual de un texto origen creole hacia un texto meta francés (DE BLUKER, 2008), o como prefiere decir Confiant, "el escritor antillano es un traductor

56 enmascarado, o más exactamente, un traductor no confesado" (CONFIANT, 2000, p. 49). En Texaco el autor antillano despliega una serie de mecanismos que cumplen efectivamente con el objetivo de alcanzar un "vértigo polisémico" producto del juego entre el rozamiento y la interacción de varias lenguas (BERNABÉ, CHAMOISEAU; CONFIANT, 2011, p. 45). Este lenguaje personal, como lo define Marie-Jose N-Zengou-Tayo, le permite al autor desplegar su creatividad manipulando las dos lenguas de una manera personal y original (1996, p. 162).

En un trabajo anterior (GHIRIMOLDI, 2017) expusimos numerosos mecanismos presentes en la obra (el uso de la partícula negativa hak, la composición de palabras, la aglutinación, el uso de arcaísmos, la inserción de palabras en creole, marcas de la oralidad) y analizamos las estrategias de traducción implementadas. Observamos en conjunto una ligera tendencia hacia la conservación del heterolingüismo, lo que demuestra que en la traducción al español prevalece la preservación de la alteridad que "compensa" otros momentos en que las estrategias de sustitución no dejan huella del original. Desde un punto de vista bermaniano, podríamos decir que la traducción de Texaco intenta, aunque no de manera sistemática, "dar albergue a lo lejano", al tender a enfatizar la especificidad lingüística y cultural del texto original (BERMAN, 1995, p.76). 


\section{Gestión de la distancia enunciativa en la traducción y ethos diferencial}

El texto heterolingüe, con sus procesos de diferenciación de lenguas, materializa una estrategia de relación con la alteridad, constituye una de las formas de "representación del discurso Otro" (SUCHET, 2009). Siguiendo la propuesta de Suchet, si consideramos el texto literario como producto de un acto de enunciación, la traducción de este texto es un acto de reenunciación. En este sentido, el heterolingüismo ofrece indicios de la presencia de un enunciador en el texto traducido, que surge en los momentos de tensión entre lenguas, creando marcas visibles en el texto traducido donde es posible entrever el trabajo del traductor. Así, el traductor, como enunciador del texto traducido, toma la responsabilidad de negociar la relación entre las lenguas. La traducción se erige como una relación de otra relación. (SUCHET, 2009).

Así como el autor del texto original construye una imagen de sí mismo en el discurso o ethos discursivo, Suchet propone pensar en la creación de un ethos autónomo del traductor en el acto de re-enunciación del texto traducido. Dicha especialista introduce el ethos diferencial, que alude a la instancia de enunciación en su relación con el texto fuente: "en un texto traducido, el ethos designa la imagen de la distancia enunciativa constitutiva de toda enunciación tal como es negociada entre el texto de llegada y el de partida" (SUCHET, 2010, p. 409).

Como explica Suchet, en la traducción de un texto heterolingüe se deja escuchar una voz de la instancia de enunciación que presenta una diferencia de grado con respecto a la de la primera enunciación. Esa diferencia depende de la manera en que se negocia la distancia entre ambas enunciaciones. La autora postula que la noción de ethos permitiría informar acerca de la manera en que el heterolingüismo construye una figura enunciativa en la intersección del texto y de su recepción (SUCHET, 2010, p. 333). El ethos designa el tipo de relación que se establece entre ambas enunciaciones, que al ser un efecto del texto meta y no una estrategia anterior a la traducción, puede manifestarse de varias maneras diferentes. Partir de los textos traducidos permite poner el acento sobre la traducción como práctica además de revelar un abanico inédito de modos de relación posibles entre los textos.

Suchet (luego del análisis de 4 novelas y 13 traducciones) distingue seis modos de negociar la distancia enunciativa:

1. Ethos de la distancia garantizada: la distancia entre el texto fuente y el texto meta es puesta en escena, vuelve a la traducción visible. El enunciador adopta la postura del garante (por ejemplo, con la nota al pie). El texto de llegada es una representación del 
texto de partida, acompañado de un discurso explicativo. El tratamiento del heterolingüismo pone de relieve el funcionamiento metatextual de la traducción.

2. Ethos del texto segundo: Se manifiesta la distancia, pero sin metadiscurso. La traducción recuerda constantemente al lector que constituye un texto segundo (con el uso de marcas tipográficas, prólogo, nota del traductor, etc.). Se rehúsa a sustituir el texto de partida. El paratexto muestra que se trata de una traducción.

3. Ethos del avatar: El enunciador hace como si fuera el narrador del texto original. El texto de llegada tiene un funcionamiento similar al texto de partida. El traductor usa las mismas estrategias.

4. Ethos del moralista: el heterolingüismo se reduce. El texto de llegada es monolingüe. La "literalidad" no se preserva. Modificación del contrato de lectura: el lector no tiene ya el rol de co-enunciador activo que esperaba el texto de partida. Es el paciente del texto de llegada. El traductor interpreta por el lector (escamotea).

5. Ethos del cuentista: algunos pasajes heterolingües se recuperan en el texto de llegada, pero la mayoría sufren modificaciones, distintas versiones del mismo cuento. Libertad de variación discursiva: el responsable del texto de llegada se asemeja a un cuentista.

6. Ethos inestable: las estrategias son tan variadas que no se puede formar una imagen coherente. Se trata cada caso en forma diferente. El heterolingüismo no se trata en función de un pacto global.

\section{Metodología}

Los fragmentos elegidos se extrajeron de la novela original en francés publicada en 1992 por Gallimard y su correspondiente traducción de la edición española de 1994 de Anagrama realizada por Emma Calatayud. En primer lugar, hemos clasificado según la estrategia de traducción (E.T.) utilizada los diversos fenómenos encontrados, señalados en negrita dentro de cada texto. En segundo término, pusimos en relación las instancias enunciativas del texto de partida y del de llegada con el objeto de identificar la presencia de una voz o ethos diferencial en el texto traducido y su caracterización dentro de un abanico de posibilidades.

Tomamos la nomenclatura de Franco Aixelá para clasificar las E.T. de los elementos culturales y la adaptamos a nuestro estudio de textos heterolingües (FRANCO AIXELÁ, 1996, p. 61-65). Para que se ajusten a nuestros elementos de análisis introducimos una ligera modificación en la presentación de las estrategias, distinguiendo dos tipos de estrategia de 
repetición, con y sin glosa extratextual. Es decir, para el caso de la estrategia de repetición del elemento heterolingüe, en la traducción hallamos dos casos: uno, en el que la grafía en cursiva remite al lector al glosario que figura al final del libro, y otro, en el que se conserva como préstamo sin explicación. Presentamos una breve definición de cada una en la siguiente tabla:

\begin{tabular}{|c|c|c|}
\hline & ESTRATEGIA & DEFINICIÓN \\
\hline \multirow{5}{*}{$\begin{array}{l}+ \\
\mathrm{C} \\
\mathrm{O} \\
\mathrm{N} \\
\mathrm{S} \\
\mathrm{E} \\
\mathrm{R} \\
\mathrm{V} \\
\mathrm{A} \\
\mathrm{C} \\
\mathrm{I} \\
\mathrm{O} \\
\mathrm{N}\end{array}$} & 1. Repetición & $\begin{array}{l}\text { Se integra la palabra o expresión del texto original (T.O.) tal cual } \\
\text { (préstamo). }\end{array}$ \\
\hline & $\begin{array}{l}\text { 2. Repetición con glosa } \\
\text { extratextual }\end{array}$ & $\begin{array}{l}\text { Se integra la palabra o expresión del T.O. tal cual (préstamo) y se ofrece } \\
\text { información remitiendo al lector a un glosario al final. }\end{array}$ \\
\hline & 3. Adaptación ortográfica & $\begin{array}{l}\text { Se adapta el mismo elemento del T.O. a la ortografía de la lengua-cultura } \\
\text { meta. }\end{array}$ \\
\hline & 4. Traducción lingüística & Se trata de un calco estructural, se conserva la forma. \\
\hline & 5. Glosa intratextual & $\begin{array}{l}\text { Se ofrece explicación dentro del texto, ayuda a evitar ambigüedad, } \\
\text { explicitar. }\end{array}$ \\
\hline \multirow{6}{*}{$\begin{array}{l}\mathrm{S} \\
\mathrm{U} \\
\mathrm{B} \\
\mathrm{S} \\
\mathrm{T} \\
\mathrm{I} \\
\mathrm{T} \\
\mathrm{U} \\
\mathrm{C} \\
\mathrm{I} \\
\mathrm{O} \\
\mathrm{N} \\
-\end{array}$} & 6. Sinonimia & Se reemplaza el elemento heterolingüe por un sinónimo. \\
\hline & $\begin{array}{l}\text { 7.Universalización } \\
\text { limitada }\end{array}$ & $\begin{array}{l}\text { Se reemplaza por un término que preserva ligeramente la alteridad del } \\
\text { original. }\end{array}$ \\
\hline & $\begin{array}{l}\text { 8. Universalización } \\
\text { absoluta }\end{array}$ & Elimina toda huella de alteridad y se substituye por una referencia neutra. \\
\hline & 9. Naturalización & $\begin{array}{l}\text { Se substituye el elemento heterolingüe por un elemento específico de la } \\
\text { lengua-cultura meta. }\end{array}$ \\
\hline & 10. Supresión & Se elimina el elemento heterolingüe. \\
\hline & 11. Creación autónoma & $\begin{array}{l}\text { Se agregan referencias culturales que no existen en el T.O. Suele } \\
\text { compensar explicaciones insuficientes en otras partes del texto. }\end{array}$ \\
\hline
\end{tabular}

Tabla 1. Clasificación de estrategias de traducción ordenadas del mayor al menor grado de conservación de los elementos heterolingües, adaptada de la nomenclatura de Franco Aixelá (1996). La tabla fue extraída de un artículo anterior (GHIRIMOLDI, 2017).

En cuanto al análisis de las distancias enunciativas entre los fragmentos elegidos de nuestro corpus, tomaremos en cuenta la clasificación de Suchet que se fundamenta en la multiplicidad de modos de relación posibles con la alteridad, un abanico no definitivo, abierto a otras formas de relación con el otro, tal como lo describimos el apartado 2. Identificaremos en cada caso, según el mayor o menor grado de conservación del heterolingüismo, la categoría de ethos que mejor se ajuste. 


\section{Análisis de las estrategias de traducción en el corpus seleccionado}

La escritura de Chamoiseau en Texaco está centrada en la historia local, en la isla donde nació, La Martinica, y sus antepasados de esclavitud, dentro de un espacio urbano, el de la ciudad de Fort-de-France. Entre los elementos que integra el autor para marcar ese localismo y reflejar las creencias de la cultura creole se encuentran la sabiduría vegetal (o medicina popular) y la magia o brujería provenientes del vudú (africano). Estas facetas del imaginario creole las recorreremos durante el análisis de los fragmentos elegidos.

\section{1 Fragmento A}

\begin{tabular}{|c|c|}
\hline Texto Original & Texto Traducido Publicado \\
\hline $\begin{array}{l}\text { Cela se crut d'autant mieux que le bougre } \\
\text { parvint un tour à se guérir d'une frappe de la } \\
\text { bête-longue. C'étaitune heure de champs. On } \\
\text { vit pourtant l'éclair de la bête à hauteur de } \\
\text { son cou. On vit pourtant l'enflure de sa veine } \\
\text { dessous sa peau grillée. On le crut pourtant } \\
\text { terrassé quand il roula dans l'herbe, roula } \\
\text { par-ci, roula par-là, arrachant telle feuille, } \\
\text { grafignant telle écorce, mâchant telle racine, } \\
\text { beuglant dans une langue inconnue une sorte } \\
\text { de chant trouble. Ramené à sa case sur le dos } \\
\text { d'un mulet, il y passa quatre jours, ou peut- } \\
\text { ettre plus, dédaignant le remède d'une } \\
\text { matrone-guérisseuse vréyée par le Béké. On } \\
\text { ne comptait pourtant plus sur lui : quand la } \\
\text { bête frappe c'est annonce-l'enterrement. } \\
\text { Mais lui, excusez, réapparut pourtant au clair } \\
\text { d'un jour de pause, pour seulement visiter une } \\
\text { sorte de pied-caümite dont le feuillage vibrait } \\
\text { des folies de vingt merle (pp. 51-52). }\end{array}$ & $\begin{array}{l}\text { Esta creencia aumentó cuando el buen } \\
\text { hombre consiguió curarse un día de una } \\
\text { mordedura de la bicha-larga. Fue a la hora } \\
\text { del trabajo en los campos. Vieron, sin } \\
\text { embargo, la marca de la bicha a la altura de } \\
\text { su cuello. Vieron, sin embargo, la hinchazón } \\
\text { de la vena bajo su piel requemada. Lo } \\
\text { creyeron fulminado, sin embargo, cuando } \\
\text { rodó por la hierba, rodó por aquí, rodó por } \\
\text { allá, arrancando una hoja, arañando una } \\
\text { corteza, mascando una raíz, mugiendo en } \\
\text { una lengua desconocida una especie de } \\
\text { confuso canto. Lo llevaron a su cabaña a } \\
\text { lomos de un mulo y pasó en ella cuatro días, } \\
\text { o tal vez más, despreciando la pócima de una } \\
\text { matrona curandera enviada por el Beké. } \\
\text { No obstante, ya nadie contaba con él: cuando } \\
\text { la bicha golpea es presagio de entierro. } \\
\text { Pero él, con perdón, reapareció tras un día de } \\
\text { pausa, sólo para visitar a una especie de } \\
\text { árbol caimita cuyas hojas vibraban con las } \\
\text { locuras de veinte mirlos (p. 44). }\end{array}$ \\
\hline
\end{tabular}

Este apartado relata un episodio vivido por el abuelo de Marie-Sophie Laborieux, la heroína de la novela, donde se destaca la sabiduría del personaje sobre el poder curativo de las plantas. En la creencia vudú se asumen relaciones mutuas que se dan entre los hombres y las fuerzas de la naturaleza. Dentro de las prácticas mágicas martiniqueñas, que toman sus orígenes, en gran parte, del vudú africano, se encuentra al "quimbois" o brujo dentro del espacio de la isla de La Martinica. Chamoiseau se identifica en la obra como narrador principal, como el Escribidor de palabras llamado Oiseau de Cham. El autor crea una relación entre su apellido y 
la brujería. Personaje de la Biblia, Cham es el hijo de Noé, quien aparece en textos medievales como el primero en practicar el arte de la brujería. (SPRENGER; INSTITORIS, 1669, apud ZDENEK, 2014, p. 38). Este juego basado en el origen etimológico de su nombre le permite al autor cubrir de un manto mágico su presencia como narrador principal.

En el pasaje elegido se retoma uno de los temas del imaginario mágico. A diferencia del vudú haitiano, los martiniqueños le temen a la serpiente, debido a una especie venenosa que ataca en los campos de cañas. Está presente en el inconsciente de los habitantes de esta isla en tal medida que hasta la palabra serpiente se convirtió en tabú y fue necesario buscar otras denominaciones. Así, las "bêtes-longues" o "cravates" eran tan temidas que el brujo que pudiese curar su mordida se ganaba la mayor reputación.

Por otra parte, al final del párrafo podemos identificar otro animal martiniqueño de importancia mágico-folclórica, el merlo. Se trata de un pájaro por el cual los brujos se sienten fascinados, criatura asociada a los fenómenos sobrenaturales y buscada por sus poderes divinos.

En la tabla 2 indicaremos los elementos heterolingües del fragmento A en el texto original (T.O.), su traducción en el texto traducido publicado (T.T.), la estrategia de traducción utilizada (E.T.), la explicación en el glosario y finalmente, en una escala de 1 a 11, del mayor al menor grado, respectivamente, de conservación del heterolingüismo en la traducción (Het.):

\begin{tabular}{|l|l|l|l|l|l|}
\hline Ej & T.O. & T.T. & E.T. & Glosario & $\begin{array}{l}\mathrm{He} \\
\text { t. }\end{array}$ \\
\hline 1 & bête-longue & Bicha-larga & Traducción lingüística. & & 4 \\
\hline 2 & matrone-guérisseuse & $\begin{array}{l}\text { matrona } \\
\text { curandera }\end{array}$ & $\begin{array}{l}\text { Universalización } \\
\text { absoluta }\end{array}$ & & 8 \\
\hline 3 & Vréyée & enviada & $\begin{array}{l}\text { Universalización } \\
\text { absoluta }\end{array}$ & & 8 \\
\hline 4 & Béké & Béké & $\begin{array}{l}\text { Repetición } \\
\text { entierro }\end{array}$ & $\begin{array}{l}\text { Blanco } \\
\text { creole }\end{array}$ & 1 \\
\hline 5 & $\begin{array}{l}\text { annonce- } \\
\text { l'enterrement }\end{array}$ & árbol caimita & Univ. Limitada & & 5 \\
\hline 6 & pied-caümite & & & \\
\hline
\end{tabular}

Tabla 2. Estrategias de traducción utilizadas en el fragmento A.

En este fragmento abunda la composición, uno de los fenómenos lingüísticos que afectan al léxico y a la semántica, un recurso que permite la creación de unidades léxicas, típica del creole y profusamente explotada en Texaco (Ej. 1, 2, 5 y 6). Es de destacar el desarrollo particular de este recurso en el campo lexical de la sociedad esclavista (nèg-de-terre) y de la fauna y la flora (bêtes-longues, écorce bois-lait-mâle, pied-caimite, etc.) detalladamente 
estudiado por Desmet Argain (2015). En el primer caso, la traducción de "bête-longue" por "bicha-larga" es una sobretraducción. En francés bête, del latín bestia, designa un animal en general, no un reptil. Y en español "bicha" es usado por las personas supersticiosas porque creen que pronunciar la palabra "víbora" o "culebra" trae mala suerte. Se conserva la estructura del original, la palabra compuesta, lo que deja asomar el heterolingüismo del original.

En los demás casos la composición desaparece ("matrona curandera", ej. 2), o se neutraliza con la adición de la preposición como estrategia explicativa ("presagio de entierro", ej. 5). También se pierde el uso del artículo antepuesto al sustantivo "l'enterrement" que sorprende al lector del original en esa posición luego de otro sustantivo "annonce" pero que evoca la aglutinación muy común en los sustantivos creoles (ej.: lajentiyes, del francés gentillesse; lajistis, del francés justice). El lector del texto traducido no podrá apreciar la presencia de dos fenómenos lingüísticos típicos del creole, recreados en la lengua francesa: la composición de palabras y la aglutinación del artículo. Sin embargo, podríamos captar como un mecanismo de compensación, por parte de la traductora, la elección de los términos "pócima" (no constituye un elemento heterolingüe) por "remède" y "presagio" por "annonce"

62 que funcionan como subjetivemas en tanto sus significados evocan la magia y la superstición, rasgos semánticos que no estaban presentes en los términos del original.

En la composición de "pied-cä̈mite" (ej. 6) se eliminan los guiones. Desaparece el término pied que recuerda al lector del original que está en presencia de un vocablo creole y es reemplazado por un elemento neutro, "árbol caimita". En glosarios técnicos encontramos como equivalente a "caïmite" usado en la Martinica, el término "caimito blanco" o "caimito morado" en países hispanohablantes como Cuba o República Dominicana. Por lo cual es posible que “árbol caimita" se trate de una universalización limitada, en el sentido que conserva levemente el heterolingüismo con la adaptación ortográfica de "caimita".

\section{2 Fragmento $B$}

\begin{tabular}{|l|l|}
\hline T.O. & T.T. Publicado \\
\hline Mais le voyage étant risqué, il se résigna au & Pero como el viaje era muy arriesgado, se \\
savoir des nèg-de-terre: frictions citron levé, & resignó con el saber de los nèg-de-terre: \\
thés mèdsinier-béni, tisane de malomain et & fricciones de limón, tés de manzanillo \\
d'écorce bois-lait-mâle. Lui-même à & bendito, infusiones de malomain y de \\
& corteza de árbol de leche macho. El se \\
\hline
\end{tabular}




\begin{tabular}{|l|l|}
\hline $\begin{array}{l}\text { longueur de journée mangea de grosses } \\
\text { caïmites comme on l'y invita (p. 158). }\end{array}$ & $\begin{array}{l}\text { pasaba el día comiendo gruesas caimitas, } \\
\text { como le aconsejaron (p. 129). }\end{array}$ \\
\hline
\end{tabular}

El fragmento B es una muestra de la sabiduría farmacológica vegetal, donde Esternome, el padre de Marie-Sophie, durante una epidemia de fiebre amarilla y ante la imposibilidad de llevar al hospital a su mujer Ninon, pone en práctica diversos procedimientos. La tabla 3 muestra las E.T. de los elementos heterolingües seleccionados.

\begin{tabular}{|l|l|l|l|l|l|}
\hline $\mathbf{E j}$ & T.O. & T.T. & E.T. & Glosario & Het \\
\hline 7 & nèg-de-terre & nèg-de-terre & $\begin{array}{l}\text { Repetición }+ \text { glosa } \\
\text { extratextual }\end{array}$ & Esclavo & 1 \\
\hline 8 & Mèdsinier-béni & $\begin{array}{l}\text { Manzanillo } \\
\text { bendito }\end{array}$ & Universal. Absoluta & & 8 \\
\hline 9 & Malomain & Malomain & Repetición & ¿? & 1 \\
\hline 10 & Bois-lait-mâle & $\begin{array}{l}\text { Árbol de leche } \\
\text { macho }\end{array}$ & Universal. Absoluta & & 8 \\
\hline 11 & Cä̈mites & Caimitas & Adaptación ortográfica & & 3 \\
\hline
\end{tabular}

Tabla 3. Estrategias de traducción utilizadas en el fragmento B.

Los nèg-de-terre eran antiguos esclavos que habían huido de las plantaciones, cultivaban la tierra y comercializaban sus productos en el mercado de los domingos (DESMET ARGAIN, 2015, p. 439). Se conserva como préstamo en la traducción y se explica en el glosario.

Para el ejemplo 8 no fue posible corroborar la correspondencia entre "mèdsinier" $\mathrm{y}$ "manzanillo". Para manzanillo, según el diccionario de árboles de Elsevier, hallamos manchineel, manchinil y manseniye en creole de las Antillas y Haití. A su vez, en creole, según el diccionario de Confiant (2007) existe “medsin", arcaísmo que significa "purga”.

Con respecto al siguiente ejemplo, la infusión de la planta de malomain o malnommée, es utilizada para bajar la fiebre, el asma, entre muchas afecciones más. Aunque aparece en cursiva, sorprendentemente, no aparece en el glosario.

Las “caïmites" corresponden en español a caimito blanco o morado, nombre del árbol y sus frutos, deliciosos y dulces, que suelen tomarse como postre. La traducción tiende a conservar el heterolingüismo pero habiendo pasado por la adaptación ortográfica. 


\section{3 Fragmento $C$}

T.O.

Sa vie s'était mise à l'abri sous une série de protègements. (...) Il avait mis à tout hasard sa chemise à l'envers. Mais la menace $n$ 'avait pas tremblé. Il regrettait sa bouteille de chenille-trèfle qui lessivait les charmes. Il regrettait ses citrons-verts-croités avec lesquels il se frottait les mains. Il regrettait son essence de kasyalata, ses plantes de verveine rouge, ses touffes de menthe glaciales, sa branche de fougère qui prévenait des visites, son basilic qui repoussait les influences, son boismoudonge que les engagés craignent, son écorce du moubin, son écorce pois-doux rouge, ses parfumages d'encens pour les Vendredi treize, son alcali, son gros éther que les soucougnan pleurent, son sel marin mélangé au charbon, sa petite pièce d'argent derrière laquelle Ninon avait noté Aragon Tétragranmakon, son carré de satin noir enveloppant un roseau et une prise de sel, sa cendre d'un jeune bambou dans $d u$ parchemin vierge, son verre neuf (gagné sans marchander) où frissonnaient encore trois gouttes de vif argent. Mon Esternome pleurait... (p. 237).

\section{T.T. Publicado}

Su vida se había refugiado bajo una serie de protecciones. (...) Se había puesto, por si acaso, la camisa del revés, pero la amenaza seguía en pie. Echaba de menos su botella de gusano-trébol que deshacía los encantamientos. $\mathrm{Y}$ sus limones verdes marcados con una cruz, con los que se frotaba las manos. Echaba de menos su esencia de kasyalata, sus plantas de verbena roja, sus matas de menta glacial, su rama de helecho que prevenía las visitas, su basilisco que rechazaba las influencias, su madera moudongue que tanto temen los iniciados, la corteza del moubin, la corteza del guisante dulce rojo, sus perfumes de incienso para los viernes y trece, su álcali, su éter que lloran los soucougnan, su sal marina mezclada con carbón, su monedita de plata, detrás de la cual Ninon había anotado Aragon Tetragranmakon, su cuadrado de raso negro que envolvía una caña y una pizca de sal, la ceniza de un joven bambú en un pergamino virgen, su vaso nuevo (ganado sin regatear) donde aún temblaban tres gotas de mercurio. Mi Esternome lloraba... (p. 193).

$\mathrm{El}$ fragmento $\mathrm{C}$ nos sumerge en el mito de aquellas mujeres maléficas que por la noche se convierten en criaturas voladoras. Esternome, para protegerse de estos peligros, hace uso de numerosos métodos del imaginario popular. La tabla a continuación muestra las estrategias utilizadas en este pasaje.

\begin{tabular}{|l|l|l|l|l|l|}
\hline Ej. & T.O. & T.T. & E.T. & Glosario & Het \\
\hline 12 & chenille-trèfle & gusano-trébol & $\begin{array}{l}\text { Traducción } \\
\text { lingüistica }\end{array}$ & 4 \\
\hline 13 & $\begin{array}{l}\text { citrons-verts- } \\
\text { croités }\end{array}$ & $\begin{array}{l}\text { limones verdes } \\
\text { marcados con } \\
\text { una cruz }\end{array}$ & $\begin{array}{l}\text { Universalización } \\
\text { absoluta }\end{array}$ & 8 & \\
\hline 14 & kasyalata & Kasyalata & $\begin{array}{l}\text { Repetición } \\
\text { Glosa } \\
\text { Extratextual }\end{array}$ & $\begin{array}{l}\text { Variedad de } \\
\text { arbusto }\end{array}$ & 2 \\
\hline
\end{tabular}




\begin{tabular}{|l|l|l|l|l|l|}
\hline 15 & Bois- moudonge & $\begin{array}{l}\text { madera } \\
\text { moudongue }\end{array}$ & $\begin{array}{l}\text { Traducción } \\
\text { literal } \\
\text { Repetición } \\
\text { (préstamo) } \\
\text { +glosa } \\
\text { extratextual }\end{array}$ & Salvaje & 2 \\
\hline 16 & moubin & moubin & Repetición & $\begin{array}{l}\text { Variedad de } \\
\text { ciruela }\end{array}$ & 1 \\
\hline 17 & soucougnan & soucougnan & Repetición & $\begin{array}{l}\text { Ser mítico } \\
\text { nacido de la la } \\
\text { metamorfosis } \\
\text { de una } \\
\text { persona, que } \\
\text { se quita la } \\
\text { piel por las } \\
\text { noches y se } \\
\text { transforma en } \\
\text { pájaro. }\end{array}$ & \\
\hline
\end{tabular}

Tabla 4. Estrategias de traducción utilizadas en el fragmento C.

En relación a la superstición, el narrador apela a una de las expresiones corrientes del creole antillano, aquella alusiva a ponerse las prendas al revés para protegerse del mal. En el diccionario de Palatin encontramos el dicho correspondiente en uso en la región: "Pour éviter les cauchemars, mettez votre chemise de nuit à l'envers" (PALATIN, 2013, p.12).

Entre varios recursos de protección mencionados en la novela, aparece en el ejemplo 12 una preparación tradicional, de probable origen amerindio, en base a alcohol, llamada "chenilletrèfle", del creole "Trèf chiniy". Se prepara a partir del gusano de un lepidóptero que parasita en las hojas del trébol (Aritolochia trilobata L.), que se pone a macerar en ron. Esta preparación, que sirve para proteger contra todos los maleficios, se vende en botellas con el gusano en el fondo del recipiente, En la traducción "gusano-trébol" se conserva la forma con el calco de estructura.

En este contexto médico-mágico, otros tratamientos contra los maleficios consisten en llevar consigo alguna hierba como talismán o ubicarla en algún lugar de la casa, e incluso cultivarla. Se privilegian las plantas amargas, como la menta glacial, (Tanacetum vulgare L.) mencionada en el fragmento. Se eligen algunas variedades por su olor alcanforado, como el basilisco (Ocimum basilicum L.), o por su aroma salvaje, como el de la madera moudongue, (Picramnia pentandra $S w$.). Se trata de una planta utilizada para alejar los malos espíritus (DESMET ARGAIN, 2015, p. 453). En el ejemplo 15 se destruye la composición "bois- 
moudonge" del original que es, a su vez, un calco del creole "bwa moudong” y en la traducción "madera moudonge" se conserva el préstamo del segundo término que remite al glosario.

En cuanto al color, se elegirán los rojos, como en el caso del "pois-doux-rouge", guisante dulce rojo. La cruz, por su parte, tiene un poder mágico, evocada en la piel de los limones, en el ejemplo 13. La composición “citrons-verts-croités" se pierde en la traducción con una universalización absoluta que explica el sentido en una extensa expresión que duplica la cantidad de elementos léxicos con "limones verdes marcados con una cruz".

La kasyalata, en el diccionario de Confiant, kasialata, corresponde en francés a cassia alata, planta medicinal usada tradicionalmente como remedio universal para diversas dermatosis. En el ejemplo 14 se repite el término y se explica en el glosario como "variedad de arbusto". Para "moubin" del ejemplo 16, encontramos la palabra creole mouben en el diccionario de Confiant, prune-moubin, fruto ovalado y amarillo, corresponde en español a la ciruela amarilla, fruta muy perfumada, pero de gusto ligeramente áspero. Los "soucougnan", según Palatin, "son personas que practican las ciencias ocultas y que se convierten en vampiros por la noche" (PALATIN, 2013, p. 30). Observamos que en el ejemplo 17, al igual que en 14,

6615 y 16, se optó por conservar el término y explicarlo en el glosario al final.

\section{Discusión de los resultados y conclusiones}

Luego de analizar el modo en que las estrategias de traducción revelan un mayor o menor grado de conservación del heterolingüismo, esbozaremos aquí algunas conclusiones que resultan de poner en relación aquellas estrategias con la gestión de la distancia enunciativa en el texto traducido.

Del análisis de los fragmentos elegidos se aprecian algunos de los mecanismos lingüísticos practicados por Patrick Chamoiseau para impregnar su escritura con la lengua y cultura creoles en el marco de las tradiciones fármaco-mágico-vegetales, en su triple faceta de escritor, traductor y etnólogo. Una escritura de tal magnitud, creativa y cargada de referentes culturales, representa un desafío indudable para quien emprenda la tarea de traducirla. Recordemos el pacto de lectura que el autor del texto propone a partir de su estilo de escritura. Como él mismo afirma en una carta dirigida a sus traductores, en su uso del francés trata de no olvidar su lengua y su imaginario creole:

Es importante que esta dimensión creole del texto permanezca, a través de las palabras, los giros, las imágenes, y hasta de ciertas fórmulas incomprensibles. No

GHIRIMOLDI. Retos de la traducción del imaginario creole: negociar la distancia enunciativa entre texto original heterolingüe y traducción

Belas Infiéis, v. 8, n. 2, pp. 51-70, 2019. DOI: 10.26512/belasinfieis.v8.n2.2019.24378 
sacrifico nada por la transparencia (ni glosario, ni notas al pie) que a mi parecer no aporta nada desde el punto de vista de la estética literaria (ARSAYE, 2004, p. 479) 5 .

La traductora de Texaco nos deja escuchar su propia voz en el texto traducido en tanto instancia de enunciación que negocia su relación con la relación de alteridad que se desprende del heterolingüismo. Pero esta relación llamada ethos diferencial no adopta siempre la misma forma, por el contrario, evidencia un movimiento oscilante entre dos posturas contrarias, por un lado, un ethos del texto segundo con huellas visibles que dejan en claro que se trata de una traducción, y por otro, un ethos que no coincide exactamente con la clasificación propuesta por Suchet y que denominamos ethos universalizante que reduce o borra el heterolingüismo del original.

El ethos del texto segundo se desprende en primer lugar de la visibilidad del texto como traducción a partir de la presencia del nombre de la traductora, Emma Calatayud, en la portada debajo del título de la obra. Luego, la traductora destaca en el texto los préstamos del creole poniéndolos en cursiva, y al final del libro, ofrece un glosario. Aunque sin discurso explicativo, la traductora deja la marca del discurso Otro en el texto e invita al lector al glosario. Sin embargo, sorprenden en algunos casos palabras en cursiva que no están en el glosario, como malomain (ejemplo 9), actitud que responde a los deseos de Chamoiseau de no confortar siempre al lector, según lo expresara en su carta a los traductores. Esta postura del ethos segundo donde se manifiesta la distancia enunciativa mostrando al lector a través de marcas tipográficas y del paratexto que se trata de una traducción se corresponden con las estrategias de conservación de los elementos heterolingües que constituyen la tendencia que prevalece ligeramente por sobre las de sustitución en la totalidad de la novela, como lo demostramos en estudios previos. El mismo resultado se observa en la breve muestra seleccionada para este artículo donde las estrategias de conservación representan el $65 \%$ del total analizado.

El ethos universalizante, a diferencia del ethos anterior, caracteriza la postura que surge en la enunciación del texto traducido que borra el heterolingüismo del texto de partida. Esta gestión de la distancia se manifiesta en la puesta en marcha de estrategias de universalización absoluta, mayoritarias entre las estrategias de sustitución del heterolingüismo. Esta postura es posible observarla en relación a la composición de palabras, uno de los fenómenos lingüísticos más usados por Chamoiseau, profusamente utilizado en la morfología de las palabras en creole. En los ejemplos 2, 8, 10 y 13 este recurso no se conserva en la traducción con lo cual el lector 
de la versión en español no percibirá las huellas de la lengua creole que sí están visibles para el lector del original.

Los textos literarios heterolingües traducidos ofrecen un terreno fértil para poner a prueba, ajustar y diseñar modelos de análisis traductológicos. La puesta en relación de las estrategias traductivas, clasificadas de acuerdo al grado de conservación del heterolingüismo, con los diferentes modos de negociación de la distancia enunciativa en el texto traducido, constituye un modo posible de abordar el estudio de la gestión de la alteridad en la traducción. Este enfoque permite considerar la relación de la traducción con el texto de partida como un efecto del texto meta y no como una intención previa del responsable de la enunciación. Además permite mostrar las diferentes posibilidades de relación con lo heterogéneo, donde lejos de adoptar una postura definitiva, la negociación de la alteridad tiene lugar dentro de un amplio abanico de fidelidades y libertades.

Esperamos haber ofrecido una pequeña muestra del desafío y los riesgos que representa la conservación de las originalidades lingüísticas y culturales de los textos heterolingües de la literatura de la creolidad. Luego del análisis y de la crítica de la traducción de unos fragmentos de Texaco, que nos hacen pensar en otras posibles versiones, en otros modos posibles de negociar la alteridad del texto original, creemos oportuno traer una reflexión de Christine Raguet. La especialista en traducción de literatura caribeña sostiene que la versión de una traducción publicada, puede ser definitiva, en el sentido de detenida en el tiempo y en el espacio, pero no definitiva en el sentido de irrevocable y exclusiva, sino que es objeto de un cuestionamiento constante (RAGUET, 2016).

\section{BIBLIOGRAFIA}

ARSAYE, Jean-Pierre. Français-créole. Créole-français. De la traduction. Ethique. Pratiques. Problèmes. Enjeux. París: L'Harmattan, 2004.

AUZÁS, Noémie. Créole magnifique: enquête sur une disparition. In: SOUVIAS, Pierre. et al. (Comp.). Patrick Chamoiseau et la mer des récits. Bordeaux: Presses Universitaires de Bordeaux, 2017. p. 109-123.

BERMAN, Antoine. La traduction et la lettre ou L'auberge du lointain. París: Editions du Seuil, 1995 (1985).

BERNABÉ, Jean; CHAMOISEAU, Patrick ; CONFIANT, Raphaël. Eloge de la créolité. París: Gallimard, 1993. 
BERNABÉ, Jean; CHAMOISEAU, Patrick y CONFIANT, Raphaël. Elogio de la creolidad. Bogotá: Editorial Pontificia Universidad Javeriana, 2011.

BERNABÉ, Jean. De la négritude à la créolité: éléments pour une approche comparée. Etudes Françaises, 28, 2-3, p. 23-38, 1992.

CHAMOISEAU, Patrick. Texaco. París : Gallimard, 1992.

CHAMOISEAU, Patrick. Texaco. Barcelona: Anagrama, 1994.

CHAMOISEAU, Patrick; CONFIANT, Raphaël. Lettres créoles. Tracées antillaises et continentales de la littérature. Haïti, Guadeloupe, Martinique, Guyane, 1635-1975. París: Gallimard, 1999.

CONFIANT, Raphaël. Traduire la littérature en situation de diglossie. Palimpsestes, n. 12, p. 49-59, 2000.

CONFIANT, Raphaël. Dictionnaire créole-français. Matoury: Ibis Rouge Editions, 2007.

DESMET ARGAIN, Céline. El translingüismo en Texaco de Patrick Chamoiseau: Implicaciones en la traducción de textos híbridos. 2015. Tesis (Doctorado) - Universidad Nacional Autónoma de México, México D.F., 2015.

FRANCO AIXELÁ, Javier. Culture-specific items in Translation. In: ALVAREZ, Román; VIDAL, María del Carmen África (Eds.). Translation, power, subversion. Clevedon/Filadelfia/Adelaide: Multingual Matters, 1996.

GHIRIMOLDI, María Eugenia. La lengua mestiza de Patrick Chamoiseau en Texaco. Análisis de las estrategias de su traducción al español. Mutatis Mutandis, 10, 1, p. 116-139, 2017.

GLISSANT, Édouard. Introduction à une Poétique du Divers. París: Gallimard, 1996.

N'ZENGOU-TAYO, Marie-José. Littérature et diglossie: créer une langue métisse ou la «chamoisification» du français dans Texaco de Patrick Chamoiseau. TTR: traduction, terminologie, rédaction, 9, 1, p. 155-176, 1996.

LEWIS, Rohan Anthony. "Langue métissée et traduction: quelques enjeux théoriques". Meta: journal des traducteurs, 48, 3. (2003): 411-420.

PALATIN, Suzy. Petit dictionnaire insolite des cultures et des langues créoles. Guadeloupe, Guyanne, Martinique. París: Larousse, 2013.

RAGUET, Christine. Desafíos heterofónicos en la traducción de la literatura caribeña. Conferencia organizada por el IdIHCS-CONICET y la AIT de la UNLP, La Plata, 18 jun. 2016.

ROSELLO, Mireille. Littérature et identité créole aux Antilles. París: Karthala, Edición digital, 2017. 
SUCHET, Myriam. La traduction, une éthique de la ré-énonciation. Nouvelle Revue d'esthétique, 1, 3, 31-35, 2009.

SUCHET, Myriam. Textes hétérolingues et textes traduits : de la langue aux figures de l'énonciation. Pour une littérature comparée différentielle. Tesis (Doctorado). 2010. Universidad de Concordia, Canadá., 2010.

ZDENEK, Pokorný. La sorcellerie et le pouvoir magique dans la littérature de l'oralité de Patrick Chamoiseau. Tesis (Doctorado). 2014. Univesidad de Masarykova, Brno, República Checa, 2014.

\footnotetext{
${ }^{1}$ María Eugenia GHIRIMOLDI. Profesora y Traductora Pública en Lengua Francesa (Universidad Nacional de la Plata). Máster 2 en Ciencias del Lenguaje (Universidad de Rouen). Máster en Investigación en Traducción e Interpretación (Universitat Jaume). Ayudante diplomada ordinaria de la Cátedra Capacitación en Francés (UNLP). Integrante del Proyecto de Investigación: "La construcción del ethos y el tratamiento de los culturemas en situación de contacto de lenguas: su articulación en el campo de la Traductología y la Didáctica de las Lenguas-Culturas Extranjeras" (UNLP, FaHCE, IdIHCS/CONICET). Universidad Nacional de La Plata. Buenos Aires, Argentina.

ORCID: https://orcid.org/0000-0002-0882-2426

E-mail: ghirimoldi.mae@gmail.com

Sitio académico: https://www.fahce.unlp.edu.ar

${ }^{2}$ Este artículo se enmmarca dentro del proyecto de investigación "La construcción del ethos y el tratamiento de los culturemas en situación de contacto de lenguas: su articulación en el campo de la Traductología y la Didáctica de las lenguas-culturas extranjeras" (H770, 2016-2020).
}

${ }^{3}$ This paper is part of the research project "La construcción del ethos y el tratamiento de los culturemas en situación de contacto de lenguas: su articulación en el campo de la Traductología y la didáctica de las lenguas-culturas extranjeras" (PI: H770, 2016-2020).

${ }^{4}$ Este artigo se insere no projeto de pesquisa "A construção do Ethos e o tratamento dos culturemas no contexto de contato entre as línguas: sua articulação no campo da Tradutologia e da Didática das Línguas Culturas Estrangeiras". (H770, 2016-2020)

${ }^{1}$ En concordancia con las traductoras del Elogio de la Creolidad (2011), G. Martin-Laprade y M.M.del V. Idárraga, adoptamos "creole" como mejor correspondencia en español del francés créole para designar a los nacidos y criados en América sin ser originarios, porque enmarca especialmente a los antillanos.

2 En oposición a la "Universalité", los creolistas proponen una "harmonisation consciente des diversités prérservées: la DIVERSALITÉ". Con esta frase culmina el texto del manifesto Eloge de la créolité, Bernabé, J. et al. (1989/1993, p. 54).

${ }^{3}$ [...] il s'érige mitan des cases à Nègres, papa-langue de l'oralité d'une culture naissante, maitre-pièce de la mécanique des contes, des titines, des proverbes, des chansons des comptines qu'il élève en littérature, ou plus exactement en oraliture. Réceptacle, relais, transmetteur ou plus exactement propagateur d'une lecture collective du monde, voici notre conteur créole. Mi traducción.

${ }^{4}$ El título de su tesis de 1988 es L'auteur en souffrance.

${ }^{5}$ Il est donc important que cette dimensión créole du texte demeure, par les mots, les tournures, les images, et meme par certaines formules incompréhensibles. Je ne sacrifie pas à la transparence (ni glossaire, ni note de bas de page) qui à mon sens n’apporte rien du point de vue de l'esthétique littéraire. (Mi traducción) 